\title{
PENERAPAN IDENTITAS VISUAL PADA MEDIA PROMOSI WEBSITE WISATA KERAJINAN RAJAPOLAH
}

\author{
Moch. Khalif Haiqal ${ }^{1}$, Syarip Hidayat ${ }^{2}$ \\ 1,2Universitas Telkom
}

\begin{abstract}
Abstrak: Potensi wisata kerajinan khususnya di Rajapolah, Kabupaten Tasikmalaya, Jawa Barat sangat besar. Rajapolah selain memiliki kerajinan anyaman yang beragam, juga memiliki kelebihan dibandingkan dengan wisata kerajinan lainnya dengan adanya wisata edukasi kerajinan di Kampung Kreatif Sukaruas. Akan tetapi dengan potensi wisata yang dimiliki Wisata Kerajinan Rajapolah, kunjungan wisatawan ke Kabupaten Tasikmalaya tidak besar dibandingkan dengan daerah sekitarnya. Wisata kerajinan Rajapolah saat ini belum memiliki identitas visual dan media promosi yang memadai. Penerapan identitas visual pada media promosi website bertujuan untuk menghasilkan media promosi yang dapat menjangkau target pasar secara luas dan efektif sekaligus memperkenalkan dan meningkatkan kesadaran akan brand wisata kerajinan Rajapolah. Metode penelitian yang digunakan menggunakan pendekatan kualitatif, sedangkan metode pengumpulan data menggunakan metode observasi, wawancara dengan narasumber terkait dan studi pustaka. Hasil analisis data menunjukkan diperlukannya media promosi berupa website yang memiliki identitas visual dari Wisata Kerajinan Rajapolah. Hasil penelitian ini adalah sebuah media promosi website Wisata Kerajinan Rajapolah dengan identitas visual yang mempresentasikan kerajinan dan wisata edukasi Rajapolah. Perancangan media promosi website ini diharapkan dapat membantu meningkatkan daya jual produk kerajinan Rajapolah dengan adanya fitur toko online dan dapat menjangkau lebih luas target pasar dari wisata kerajinan Rajapolah.
\end{abstract}

Kata kunci: Brand Identity, Rajapolah, Website, Wisata Kerajinan

\begin{abstract}
Handicraft tourism especially in Rajapolah, Kabupaten Tasikmalaya, West Java has a lot of potential. In addition to the various wicker crafts, the craft educational tourism in Kampung Kreatif Sukaruas, makes Rajapolah has advantages compared with other craft tours. However, with the tourism potential of Rajapolah Handicraft Tours, tourist visits to Tasikmalaya Regency is not large compared to the surrounding area.Handicraft centers in Indonesia are very numerous and scattered in
\end{abstract}

Penulis adalah mahasiswa dan staf pengajar jurusan Desain Komunikasi Visual, Fakultas Industri Kreatif Universitas Telkom, email: khalifhaikal@gmail.com, syarip@telkomuniversity.ac.id 
various regions with their respective superior products, but not many that have the visual identity and media campaigns to attract tourists to visit. This study uses the qualitative research method with several methods of data collection including observations, interviews with relevant sources and literature study. The results from analysis data shows that promotion media in the form of a website that has a visual identity of Rajapolah Handicraft Tour. The results of data analysis indicate the need of promotion media in the form of websites that have a visual identity of Rajapolah Handicraft Tour. The selection of websites as a promotion media based on the use of digital media and the Internet that is growing in the community today so that it can reach broad target market. The result of this research is a media promotion website of Rajapolah Handicraft Tour with visual identity presenting craft and educational tour of Rajapolah. The design of website promotion media is expected to help attract tourists to visit Rajapolah craft tourism.

Keywords: Brand Identity, Craft Tourism, Rajapolah, Website

\section{PENDAHULUAN}

Rajapolah berada di utara Kabupaten Tasikmalaya sudah terkenal sebagai daerah sentra kerajinan tangan di Jawa Barat. Memiliki posisi yang strategis di jalur selatan pulau jawa yang menghubungkan provinsi Jawa Barat dengan provinsi Jawa Tengah membuat kecamatan Rajapolah memiliki potensi yang besar bagi warga setempat. Sentra Kerajinan Rajapolah memiliki berbagai macam kerajinan tangan mulai dari barang-barang dekorasi seperti tikar, kotak perhiasan, bingkai foto dll. hingga barang-barang fungsional seperti tas, keranjang, sandal, dan peralatan rumah tangga lainnya. Rajapolah juga memiliki wisata edukasi kerajinan yang berada di Kampung Kreatif Sukaruas. Kampung Kreatif Sukaruas merupakan gagasan dan inisiatif dari warga setempat yang berusaha mengembangkan potensi yang ada di kampungnya yang merupakan sebagai sentra pembuatan kerajinan di Rajapolah. Dalam melakukan kegiatannya warga Kampung Sukaruas mendirikan Paguyuban Kampung Kreatif Sukaruas (PKKS) sebagai tempat untuk menampung ide-ide kreatif warga yang merupakan sebagian besar adalah perajin anyaman. 
Dengan potensi kerajinan yang beragam dan juga memiliki wisata edukasi kerajinan, membuat Wisata Kerajinan Rajapolah memiliki potensi yang lebih besar dibandingkan dengan wisata kerajinan lainnya.

Potensi wisata yang dimiliki Rajapolah seharusnya dapat meningkatkan kunjungan wisatawan ke Kabupaten Tasikmalaya. Akan tetapi berdasarkan data dari Dinas Pariwisata dan Kebudayaan Provinsi Jawa Barat menunjukkan dari 39.246.588 wisatawan yang mengunjungi Provinsi Jawa Barat pada tahun 2015 hanya 1.478 .251 wisatawan atau $3,5 \%$ saja yang berkunjung ke Kabupaten Tasikmalaya. Jumlah tersebut lebih kecil dibandingkan dengan daerah lain di sekitar Kabupaten Tasikmalaya. Maka dari itu salah satu cara untuk meningkatkan kunjungan wisatawan yaitu dengan melakukan kegiatan promosi melalui suatu media. Menurut Darmastuti (2012:22-23) media mempunyai peranan yang besar dalam memengaruhi masyarakat baik pengaruh positif maupun negatif. Oleh karena itu penggunaan media dalam kegiatan promosi dibutuhkan untuk dapat mempengaruhi target pasar agar mengunjungi Wisata Kerajinan Rajapolah. Sedangkan berdasarkan wawancara dengan ketua PKKS, Bapak Ade Abu Bakar menyatakan bahwa saat ini belum adanya bantuan maupun kerjasama dari pihak Dinas Pariwisata Kabupaten Tasikmalaya dalam mempromosikan wisata kerajinan Rajapolah. George E. Belch dan Michael A. Belch berpendapat dalam menyampaikan pesan promosi kepada calon pembeli atau pengguna dari suatu produk maupun brand terdapat Perencanaan media sebagai rangkaian pengambilan keputusannya. Dalam perencanaan media terdapat salah satu strategi yaitu Target Market Coverage (Cakupan Target Pasar) Dalam perencanaan media, target pasar harus dapat dicapai seluas-luasnya, oleh karena itu dibutuhkan suatu media yang dapat menyampaikan pesan kepada target pasar dengan tepat (Belch dan Belch, 2012:331-359). 
Media promosi website dipilih sebagai media promosi wisata kerajinan Rajapolah karena merupakan salah satu media yang dianggap efektif dalam menjangkau target pasar yang luas dikarenakan website dapat diakses kapanpun dan dimanapun melalui internet yang kini telah banyak digunakan oleh masyarakat. Dengan website wisata kerajinan ini target pasar dapat mengetahui informasi tentang wisata kerajinan yang ada di Rajapolah. Selain informasi wisata, website juga memiliki fasilitas belanja online sebagai cara mempromosikan kerajinan Rajapolah sehingga target pasar dapat mencoba produk terlebih dahulu sebelum memutuskan untuk mengunjungi Wisata Kerajinan Rajapolah di kemudian hari. Dalam merancang media promosi website diperlukan juga identitas visual dalam keseluruhan desain dan tampilan yang disajikan. Penerapan identitas visual pada website dapat menciptakan suatu persepsi pada identitas Wisata Kerajinan Rajapolah sehingga meningkatkan kesadaran terhadap brand dan menjadi unsur pembeda dari pesaing.

\section{KAJIAN TEORI}

Alina Wheeler berpendapat bahwa brand merupakan suatu cara dari perusahaan untuk dapat terhubung dengan konsumen, menjadi tak tergantikan dan menciptakan hubungan yang lama (Wheeler, 2013:2). Oleh karena itu dibutuhkan suatu brand untuk dapat menghubungkan Wisata Kerajinan Rajapolah dengan target pasar yang dituju. Identitas visual dapat mempermudah kesadaran dan pengenalan terhadap suatu brand. Identitas visual memicu persepsi dan mengembangkan asosiasi terhadap suatu brand. Indera penglihatan memberikan lebih banyak informasi tentang dunia dibandingkan dengan panca indera lainnya (Wheeler, 2013:50). Perancangan identitas visual dan media promosi website ini, menggunakan prinsip dan elemen-elemen desain berupa bentuk, warna, ilustrasi,

tipografi dan layout. Menurut Wibowo, tipografi merupakan ilmu yang mempelajari bentuk huruf, dimana huruf, angka, tanda baca, dan sebagainya tidak 
hanya dilihat sebagai simbol suara, tetapi dilihat sebagai bentuk desain (Wibowo, 2013:115). Layout yang baik memperhatikan penyusunan dari setiap elemenelemen desain yang berhubungan ke dalam sebuah bidang sehingga membentuk susunan yang artistik (Amborse \& Harris, 2005 dalam Anggraini dan Natalia, 2014:74-77).

Proses merancang website terdapat tiga tahap yaitu pertama Discovery mengumpulkan informasi tentang pemberi proyek. Kedua Exploration menganalisa informasi yang didapatkan dan bereksperimen menyusun informasi, produk atau layanan yang akan ditampilkan. Dan ketiga Implementation mulai membuat sketsa dan mendesain layout website (Beaird dan George, 2014:2-4). Menurut Jason Beaird dan James George, website memiliki beberapa komponen yang membentuk kesatuan anatomi website, diantaranya adalah Containing block yaitu tempat/area untuk meletakkan seluruh konten halaman web. Lebar dari container ini bisa berubah-ubah atau pasti sesuai dengan ukuran layar monitor. Logo merupakan komponen penting yang diletakkan sebagai identitas sebuah perusahaan/lembaga agar dikenal oleh orang yang mengakses website tersebut. Navigation yaitu sistem navigasi menu pada website biasanya berada di kanan atau atas halaman web agar mudah ditemukan oleh pengguna. Sebaiknya navigasi berada sedekat mungkin dengan bagian atas layout. Content, penting untuk menjaga konten utama dalam web sebagai titik fokus dari desain karena pengunjung website akan selalu membutuhkan informasi-informasi penting yang dapat dengan mudah diakses. Footer, berada di bawah halaman web yang biasanya terdiri dari copyright, kontak, dan informasi. Whitespace, ruang kosong yang diperlukan dalam sebuah halaman website agar pengunjung dapat melihat halaman dengan nyaman dan agar tercipta keseimbangan serta kesatuan antar elemen desain. 


\section{METODE PENELITIAN}

Penelitian dan perancangan ini menggunakan pendekatan kualitatif, sedangkan metode pengumpulan data melalui observasi, wawancara, dan studi pustaka. Observasi dilakukan pada objek penelitian yang bersangkutan yaitu Wisata Kerajinan Rajapolah di Kabupaten Tasikmalaya. Wawancara kepada narasumber terkait, Bapak Ade Abu Bakar dan Dinas Pariwisata Pemuda dan Olahraga Kabupaten Tasikmalaya. Studi pustaka dilakukan dengan mengumpulkan teori yang mendukung penelitian serta data pesaing sejenis dari buku dan internet. Analisis perbandingan dilakukan terhadap visual dan media promosi website pesaing yang sudah ada sebelumnya yaitu Craft Scotland, Kanazawa Craft Tourism dan Lanna Handicraft Tourism.

\section{HASIL DAN DISKUSI}

Hasil observasi menunjukkan Rajapolah mempunyai keunggulan pada produk kerajinan anyaman yang beragam dari jenis produk hingga bahan baku yang digunakan. Akan tetapi wisata kerajinan Rajapolah sama sekali belum memiliki identitas visual yang dapat diterapkan pada media promosinya untuk dapat menarik wisatawan berkunjung dibandingkan dengan proyek sejenis lainnya.

Tabel 1 Analisis Tinjauan Proyek Sejenis

\begin{tabular}{|c|c|c|c|}
\hline Kriteria & Craft Scotland & Kanazawa Craft Tourism & $\begin{array}{c}\text { Lanna Handicraft } \\
\text { Tourism }\end{array}$ \\
\hline 1. Logo & & 金沢 ワラフト・ツーリ & \\
\hline $\begin{array}{l}\text { 2. Lokasi } \\
\text { Wisata }\end{array}$ & $\begin{array}{l}\text { Tersebar di seluruh } \\
\text { wilayah Skotlandia }\end{array}$ & $\begin{array}{ll}\text { Tersebar di Kota } \\
\text { Kanazawa, Jepang }\end{array}$ & $\begin{array}{l}18 \text { Desa di Bagian Utara } \\
\text { (Lanna) Thailand }\end{array}$ \\
\hline 3. Media & $\begin{array}{ll}- & \text { Website } \\
\text { - } & \text { Media Sosial } \\
\end{array}$ & $\begin{array}{ll}- & \text { Website } \\
\text { - } & \text { Brosur } \\
\end{array}$ & - Website \\
\hline $\begin{array}{l}\text { 4. Jenis } \\
\text { Wisata } \\
\end{array}$ & $\begin{array}{ll}- & \text { Belanja } \\
- & \text { Edukasi } \\
\end{array}$ & $\begin{array}{ll}\text { - } & \text { Belanja } \\
\text { - } & \text { Edukasi } \\
\end{array}$ & $\begin{array}{ll}\text { - } & \text { Belanja } \\
\text { - } & \text { Edukasi } \\
\end{array}$ \\
\hline
\end{tabular}




\begin{tabular}{|l|ll|ll|l|}
\hline & - & Perhiasan & - & Keramik & - \\
5. Jenis & - & Gelas & - & Tekstil & Tembikar \\
Kerajin & - & Keramik & - & Bordir & - Tenun \\
an & - & Tekstil & - Ukiran & - Perak \\
& - Anyaman & & & - Anyaman Bambu \\
\hline
\end{tabular}

sumber: dokumentasi pribadi

Data ketiga proyek sejenis menunjukkan penggunaan media website dipilih sebagai media promosi wisata kerajinan. Ketiga proyek sejenis juga memiliki identitas visual dengan ciri khasnya masing-masing.

Tabel 2 Analisis Identitas Visual Proyek Sejenis

\begin{tabular}{|c|c|c|c|}
\hline Kriteria & Craft Scotland & $\begin{array}{c}\text { Kanazawa Craft } \\
\text { Tourism }\end{array}$ & Lanna Handicraft Tourism \\
\hline 1. Logo & SCOTLAND & 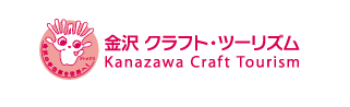 & 3 \\
\hline $\begin{array}{l}\text { 2. Jenis } \\
\text { Logo }\end{array}$ & Letter mark & $\begin{array}{l}\text { Picture mark dan Letter } \\
\text { mark }\end{array}$ & $\begin{array}{l}\text { Picture mark dan Letter } \\
\text { mark }\end{array}$ \\
\hline 3. Ilustrasi & $\begin{array}{l}\text { Sederhana hanya } \\
\text { menggunakan tipografi } \\
\text { saja sebagai logo }\end{array}$ & $\begin{array}{l}\text { Menggunakan suatu } \\
\text { ikon dari maskot yang } \\
\text { mempunyai bentuk } \\
\text { dari telapak tangan. }\end{array}$ & $\begin{array}{l}\text { Simbol pohon } \\
\text { mempresentasikan } \\
\text { keselarasan dengan alam } \\
\text { sekaligus sebagai sumber } \\
\text { dari bahan-bahan } \\
\text { kerajinan yang ada }\end{array}$ \\
\hline 4. Warna & $\begin{array}{l}\text { Warna hitam } \\
\text { memberikan kesan } \\
\text { formal, profesional dan } \\
\text { modern yang } \\
\text { mempresentasikan Craft } \\
\text { Scotland sebagai tempat } \\
\text { kerajinan kontemporer. }\end{array}$ & $\begin{array}{l}\text { Warna merah muda } \\
\text { diambil dari warna } \\
\text { bunga sakura } \\
\text { melaambangkan } \\
\text { simbol dari acara } \\
\text { musim semi yang ada } \\
\text { di Kanazawa } \\
\end{array}$ & $\begin{array}{l}\text { Warna kuning } \\
\text { melambangkan } \\
\text { kegembiraan dan } \\
\text { kebahagiaan } \\
\text { Warna merah muda } \\
\text { melambangkan feminim } \\
\text { dan kesukacitaan. }\end{array}$ \\
\hline $\begin{array}{l}\text { 5. Tipogra- } \\
\mathrm{fi}\end{array}$ & $\begin{array}{ll}\text { - } & \text { Tipe Font: Serif dan } \\
\text { Sans Serif } \\
\text { - } & \text { Readability, tingkat } \\
\text { keterbacaan dapat } \\
\text { dipahami dengan } \\
\text { cukup mudah } \\
\text { - } \quad \text { Clearity, jelas dengan } \\
\text { memiliki } 2 \text { jenis font } \\
\text { - } \quad \text { Visibility, dapat } \\
\text { dilihat } \\
\text { - } \quad \text { Legibility, komposisi } \\
\text { logo yang baik } \\
\text { berdasarkan ukuran, } \\
\text { jenis huruf, kontras }\end{array}$ & $\begin{array}{ll}\text { - } & \text { Tipe Font: Serif } \\
\text { - } & \text { Readability, tingkat } \\
\text { keterbacaan dapat } \\
\text { dipahami dengan } \\
\text { cukup mudah } \\
\text { - } \quad \text { Clearity, jelas } \\
\text { dengan memiliki } 1 \\
\text { jenis font } \\
\text { - } \quad \text { Visibility, dapat } \\
\text { dilihat } \\
\text { - } \quad \text { Legibility, } \\
\text { komposisi logo } \\
\text { yang baik } \\
\text { berdasarkan }\end{array}$ & $\begin{array}{ll}\text { - } & \text { Tipe Font: Serif } \\
\text { - } & \text { Readability, tingkat } \\
\text { keterbacaan dapat } \\
\text { dipahami dengan } \\
\text { cukup mudah } \\
\text { - } \quad \text { Clearity, jelas dengan } \\
\text { memiliki } 1 \text { jenis font } \\
\text { - } \quad \text { Visibility, penggunaan } \\
\text { warna yang tidak } \\
\text { kontras } \\
\text { - Legibility, komposisi } \\
\text { ukuran logogram } \\
\text { dengan logotype } \\
\text { kurang seimbang }\end{array}$ \\
\hline
\end{tabular}




\begin{tabular}{|c|c|c|c|}
\hline & $\begin{array}{l}\text { warna yang } \\
\text { digunakan }\end{array}$ & $\begin{array}{l}\text { ukuran, jenis huruf, } \\
\text { kontras warna } \\
\text { yang digunakan }\end{array}$ & \\
\hline Kriteria & Craft Scotland & $\begin{array}{c}\text { Kanazawa Craft } \\
\text { Tourism }\end{array}$ & Lanna Handicraft Tourism \\
\hline $\begin{array}{l}\text { 6. Deskrip } \\
\text { si }\end{array}$ & $\begin{array}{l}\text { Penggunaan logotype } \\
\text { dan warna hitam sebagai } \\
\text { logo menggambarkan } \\
\text { kesan modern, } \\
\text { kontemporer dan } \\
\text { dinamis. Citra modern } \\
\text { yang berusaha } \\
\text { ditunjukkan dalam logo } \\
\text { Craft Scotland diambil } \\
\text { dari citra kerajinan di } \\
\text { Skotlandia yakni bukan } \\
\text { hanya sebagai pusat } \\
\text { kerajinan tradisional } \\
\text { tetapi juga sebagai pusat } \\
\text { kerajinan kontemporer } \\
\text { dimana memadukan } \\
\text { kerajinan tradisional } \\
\text { dengan seni modern. }\end{array}$ & $\begin{array}{l}\text { Logo Kanazawa Craft } \\
\text { Tourism terdiri dari } \\
\text { logogram dan logotype } \\
\text { berwarana merah } \\
\text { muda. Logotype } \\
\text { menggunakan dua } \\
\text { penulisan yakni dengan } \\
\text { aksara kana/ aksara } \\
\text { Jepang untuk } \\
\text { memudahkan } \\
\text { wisatawan lokal dan } \\
\text { penulisan penulisan } \\
\text { alphabet dengan } \\
\text { bahasa inggris untuk } \\
\text { memudahkan } \\
\text { wisatawan } \\
\text { mancanegara }\end{array}$ & $\begin{array}{l}\text { Logo terdiri dari logogram } \\
\text { sebuah pohon yang } \\
\text { dipresentasikan sebagai } \\
\text { sumber kehidupan. } \\
\text { Komposisi yang tidak } \\
\text { konsisten antara logogram } \\
\text { dengan logotype kurang } \\
\text { sesuai dimana dibawah } \\
\text { logogram sudah terdapat } \\
\text { logotype akan tetapi } \\
\text { logotype yg lebih besar } \\
\text { juga ditambahkan disisi } \\
\text { logogram }\end{array}$ \\
\hline
\end{tabular}

sumber: dokumentasi pribadi

Identitas visual dari setiap wisata kerajinan menggambarkan konsep visual dan tema dari masing-masing daerah pariwisata. Setiap logo memiliki ciri khas yang berbeda satu sama lain yang menggambarkan identitas daerahnya masingmasing. Oleh karena itu wisata kerajinan Rajapolah membutuhkan suatu identitas visual yang menggambarkan konsep dan tema berdasarkan ciri khas daerahnya, sehingga identitas dari wisata kerajinan Rajapolah Kabupaten Tasikmalaya mempunyai ciri khas dan pembeda dari pariwisata yang lain.

\section{Konsep Perancangan}

Perancangan identitas visual wisata kerajinan Rajapolah memiliki konsep pesan utama yaitu "Rajapolah sebagai destinasi wisata belanja dan edukasi kerajinan anyaman". Berdasarkan pesan tersebut maka didapatkan empat kata kunci yang mempresentasikan identitas dari Rajapolah yaitu, Local Content, Mengedukasi, Anyaman, dan Wadah Kreatifitas. Local Content, menggambarkan 
asal daerah dari kerajinan Rajapolah sehingga identitas dapat dengan mudah diasosiasikan dan dikenal. Mengedukasi, mengenalkan salah satu potensi dariwisata kerajinan Rajapolah sebagai wisata edukasi. Anyaman, mempromosikan kerajinan unggulan anyaman dari Rajapolah. Wadah Kreatifitas, menampung ide-ide dari para perajin kerajinan dan juga sebagai tempat menyalurkan kreatifitas para pengunjung. Keempat kata kunci tersebut menjadi landasan dalam menyusun konsep visual.

Konsep visual mengambil bentuk logo Picture Mark dan Letter Mark yaitu kombinasi dari elemen gambar dan tulisan yang terpisah. Elemen gambar logo wisata kerajinan Rajapolah memiliki 3 unsur yaitu bentuk wadah, bentuk daun dan bentuk aksara sunda.

Bentuk kubus diambil dari fungsi pada salah satu kerajinan anyaman Rajapolah yakni anyaman wadah seperti kotak perhiasan, kotak tisu, tas, keranjang dan peralatan rumah tangga lainnya. Bentuk kubus dari wadah ini juga memiliki filosofi yang menjadikan wisata kerajinan Rajapolah selain sebagai sentra kerajinan anyaman melainkan juga sebagai sarana edukasi kerajinan yang mewadahi ide-ide dan kreatifitas para perajin anyaman dan pengunjung di Rajapolah.

Bentuk daun menggambarkan hubungan dengan alam, dimana bahanbahan dasar yang digunakan dalam proses pembuatan kerajinan anyaman Rajapolah merupakan dari serat alami salah satunya adalah serat eceng gondok dan bambu yang ramah lingkungan.

Bentuk aksara sunda yang mewakili kebudayaan Sunda yang ada di Rajapolah. Bentuk visual aksara sunda tersebut distilasi dan disesuaikan pada bentuk daun. Aksara yang digunakan merupakan inisial dari Rajapolah yaitu Ra, Ja dan Pa. 


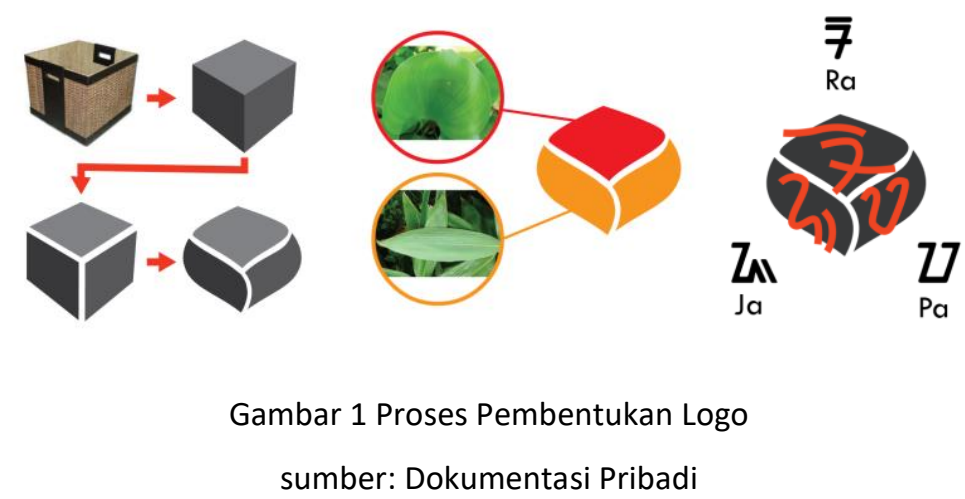

Pemilihan warna merupakan salah satu pembentuk karakter dari suatu identitas visual, oleh karena itu pemilihan warna untuk logo wisata kerajinan Rajapolah disesuaikan pada salah-satu karakter yang dimiliki Rajapolah yaitu unsur alami. Warna-warna tersebut diambil dari warna serat alami yang telah dijemur dan dijadikan anyaman yang umumnya berwarna kuning kecoklatan.

Setelah semua bentuk dasar disatukan dan dilakukan stilasi dengan akasara sunda kemudian tipografi ditambahkan pada logo.

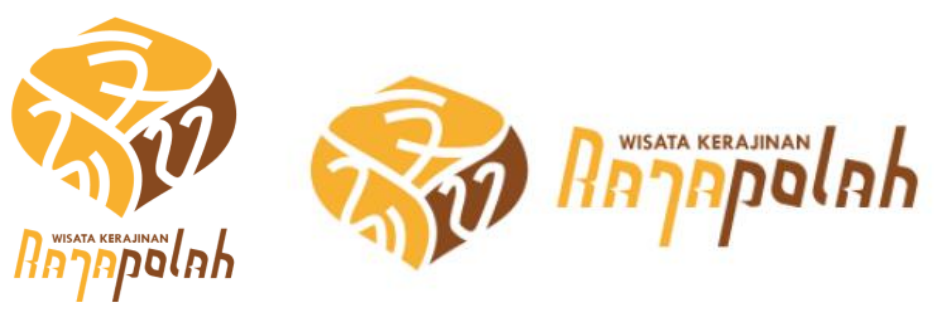

Gambar 2 Logo Horizontal dan Vertikal Wisata Kerajinan Rajapolah sumber: Dokumentasi Pribadi

Tiga buah motif dirancang dari tiga bentuk aksara sunda berdasarkan inisial Rajapolah yaitu Ra, Ja dan Pa. Motif tersebut digunakan dengan cara disusun sehingga membentuk pola, penggunaan motif dimaksudkan sebagai pendamping identitas visual wisata kerajinan Rajapolah dengan memberikan karakter serta kesan estetika pada identitas wisata kerajinan Rajapolah. 


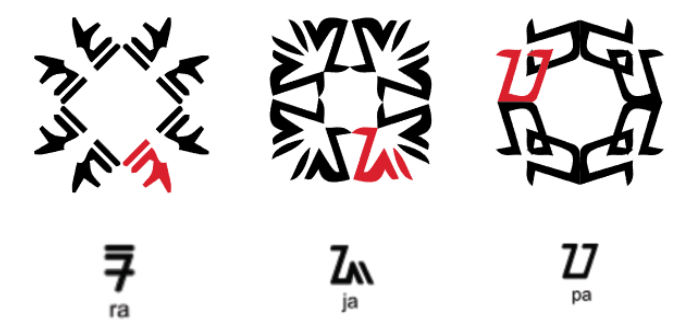

Gambar 3 Pola dari Aksara Sunda sumber: Dokumentasi Pribadi

\section{Hasil Perancangan}

Website yang telah dirancang berdasarkan dari identitas visual mempunyai lima halaman utama yaitu:

1. Beranda

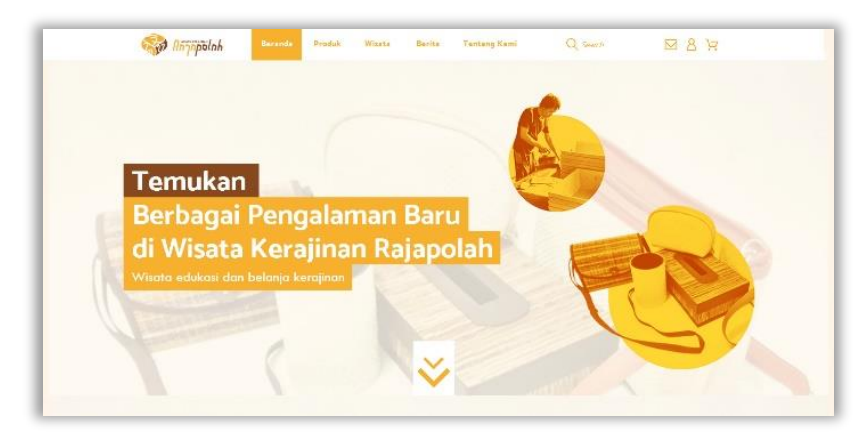

Gambar 4 Halaman Beranda sumber: Dokumentasi Pribadi

Beranda merupakan halaman utama dari website promosi wisata kerajinan Rajapolah dan merupakan halaman pertama yang dikunjungi ketika mengakses website. Halaman beranda memiliki informasi dan tampilan sekilas dari setiap halaman website lainnya yang bertujuan untuk dapat menarik pengunjung website untuk dapat menjelajahi website secara keseluruhan. 
2. Produk

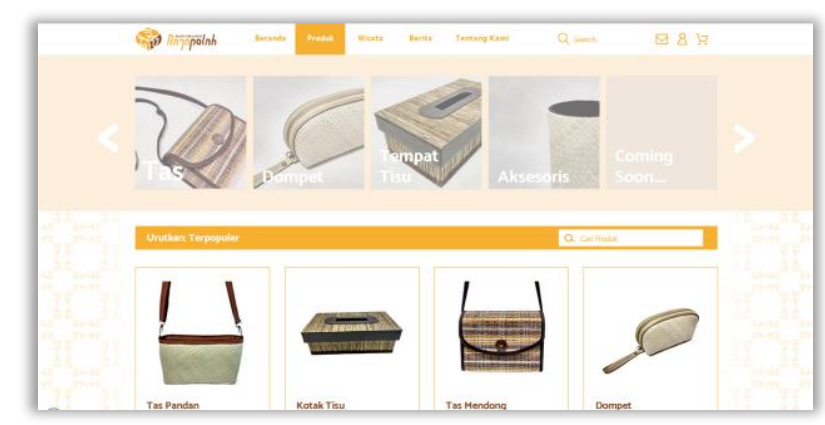

Gambar 5 Halaman Produk

sumber: Dokumentasi Pribadi

Halaman produk merupakan tempat mempromosikan beragam kerajinan tangan Rajapolah. Fitur toko online ini diharapkan dapat meningkatkan daya jual kerajinan Rajapolah. Informasi setiap produk ditampilkan secara lengkap dan pengunjung juga dapat langsung membeli produk secara online.

3. Wisata

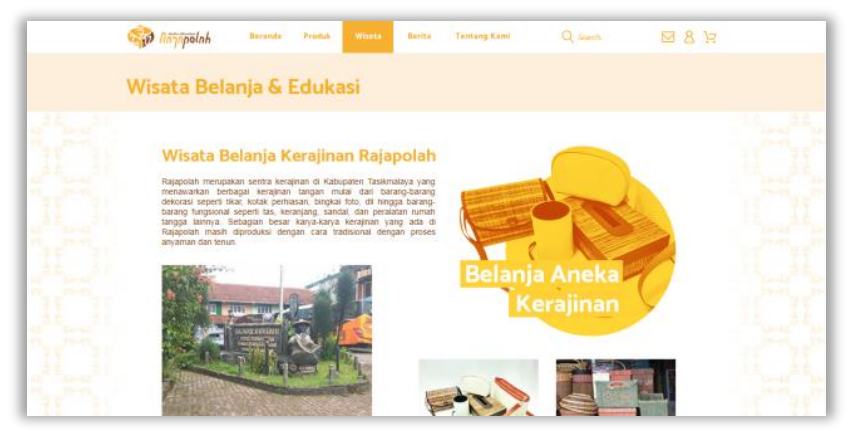

Gambar 6 Halaman Wisata

sumber: Dokumentasi Pribadi

Pada halaman ini berisi informasi mengenai wisata kerajinan dan wisata edukasi secara lengkap bagi pengunjung yang tertarik mengunjungi wisata kerajinan Rajapolah. 
4. Berita

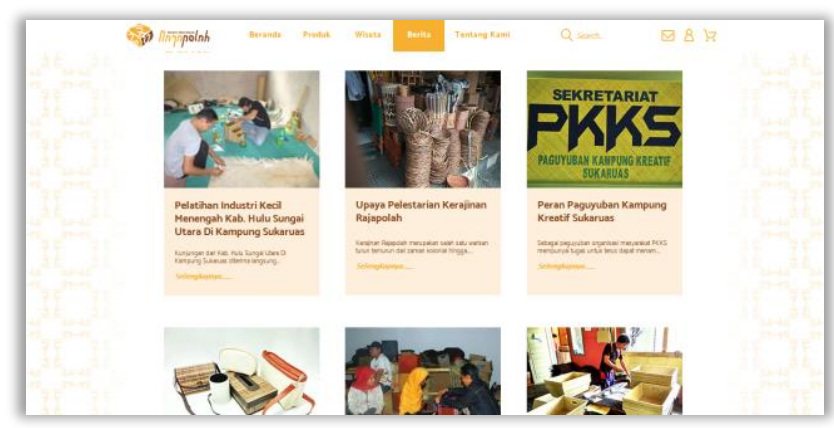

Gambar 7 Halaman Berita sumber: Dokumentasi Pribadi

Website wisata kerajinan Rajapolah juga menyediakan informasi dan berita terbaru yang berkaitan dengan kerajinan maupun wisata di Rajapolah dan sekitarnya.

5. Tentang Kami

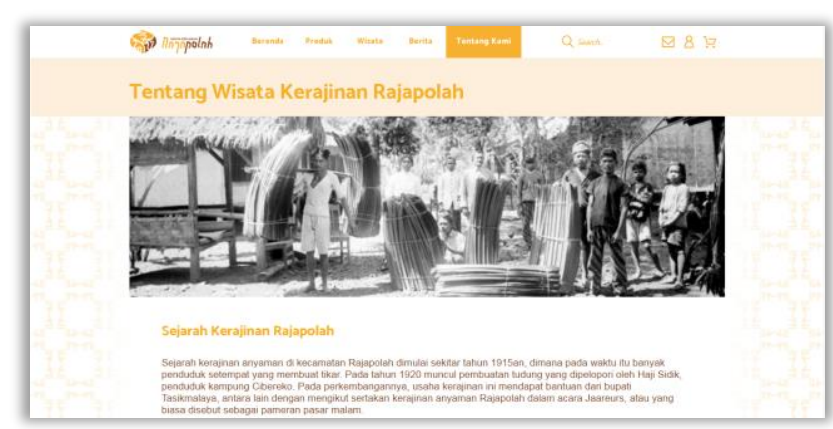

Gambar 8 Halaman Tentang Kami

sumber: Dokumentasi Pribadi

Halaman tentang kami berisi profil, sejarah dan asal-usul dari wisata kerajinan Rajapolah. Halaman ini juga memiliki alamat dan kontak yang dapat dihubungi oleh pengunjung jika membutuhkan informasi yang lebih lengkap. 
Perancangan media promosi website wisata kerajinan Rajapolah disusun dari komponen-komponen utama yaitu:

Tabel 3 Anatomi Website

\begin{tabular}{|c|c|c|}
\hline Komponen & Visual & Keterangan \\
\hline $\begin{array}{l}\text { Containing } \\
\text { Block }\end{array}$ & 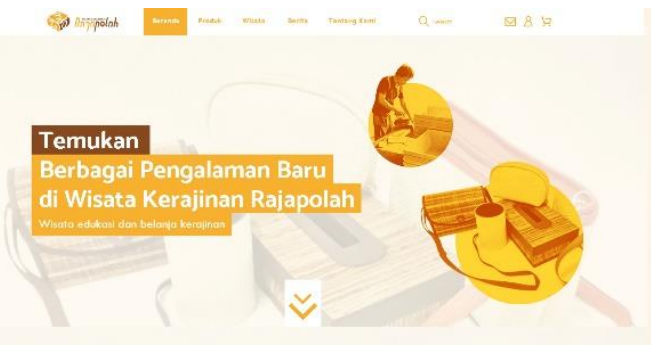 & $\begin{array}{l}\text { Ukuran area konten } \\
\text { website Rajapolah } \\
\text { memiliki ukuran yang fluid } \\
\text { yaitu berubah-ubah } \\
\text { menyesuaikan dengan } \\
\text { layar monitor }\end{array}$ \\
\hline Logo & (9) $)(1)$ Rinhpolnh Beranda Produk Wisata & $\begin{array}{l}\text { Logo ditempatkan pada } \\
\text { sisi kiri atas sejajar dengan } \\
\text { menu navigation website } \\
\text { agar dapat terlihat } \\
\text { disetiap halaman pada } \\
\text { website }\end{array}$ \\
\hline Navigation & 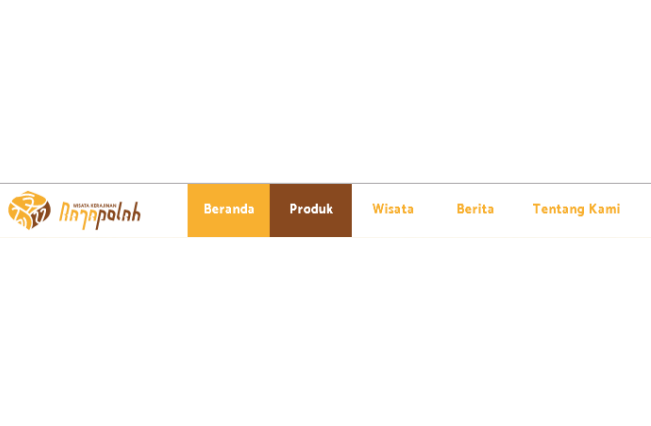 & $\begin{array}{l}\text { Menu navigasi memiliki } \\
\text { background berwarna } \\
\text { putih dengan warna } \\
\text { tombol yang } \\
\text { menyesuaikan dengan } \\
\text { warna identitas visual } \\
\text { wisata kerajinan Rajapolah }\end{array}$ \\
\hline Content & 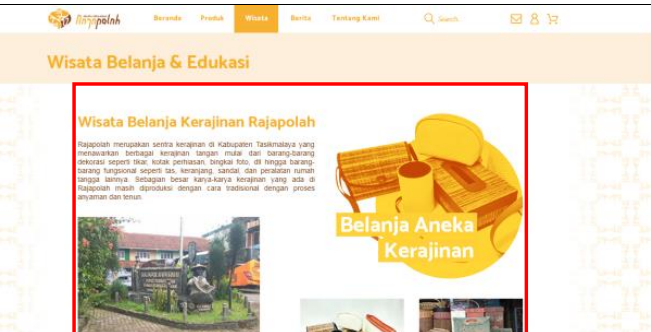 & $\begin{array}{l}\text { Konten utama website } \\
\text { terletak di tengah-tengah } \\
\text { halaman website agar } \\
\text { memudahkan pengunjung } \\
\text { dalam mencari informasi }\end{array}$ \\
\hline Footer & 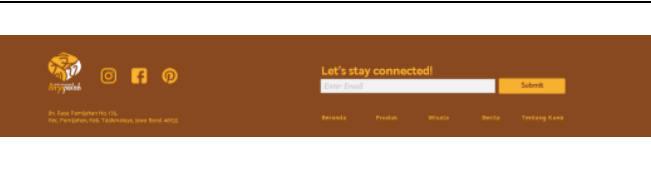 & $\begin{array}{l}\text { Terletak di bagian akhir } \\
\text { halaman website, footer } \\
\text { memiliki warna }\end{array}$ \\
\hline
\end{tabular}




\begin{tabular}{|l|l|l|}
\hline Whitespace & & $\begin{array}{l}\text { background coklat tua } \\
\text { menyesuaikan terhadap } \\
\text { warna dari identitas visual }\end{array}$ \\
\hline & Ruang kosong pada \\
website terletak di kedua \\
sisi kiri dan kanan pada \\
setiap halaman website. \\
Ruang kosong pada
\end{tabular}

sumber: dokumentasi pribadi

Setiap komponen dari website wisata kerajinan Rajapolah memiliki bentuk dan warna yang mengikuti dari identitas visual yang telah dirancang sebelumnya. Perancangan media promosi website wisata kerajinan Rajapolah ini menggunakan prinsip dasar desain berupa layout, tipografi, ilustrasi dan warna.

Tabel 4 Penerapan Teori pada Website

\begin{tabular}{|c|c|c|}
\hline Teori & Visual & Keterangan \\
\hline Tipografi & $\begin{array}{l}\text { Ragam Kerajinan Anyaman } \\
\text { Asli Indonesia ada di Rajapolah } \\
\text { Wisata kerajinan Rajapolah menawarkan berbagai macam produk anyaman asli } \\
\text { dengan wisata edukasi proses pembuatan kerainan di Kampung Kreatif Sukaruas }\end{array}$ & $\begin{array}{l}\text { Penggunaan tipografi } \\
\text { pada website } \\
\text { menggunakan huruf sans- } \\
\text { serif yang lebih mudah } \\
\text { dibaca pada layar monitor } \\
\text { sehingga lebih nyaman } \\
\text { dibaca oleh pengunjung }\end{array}$ \\
\hline
\end{tabular}




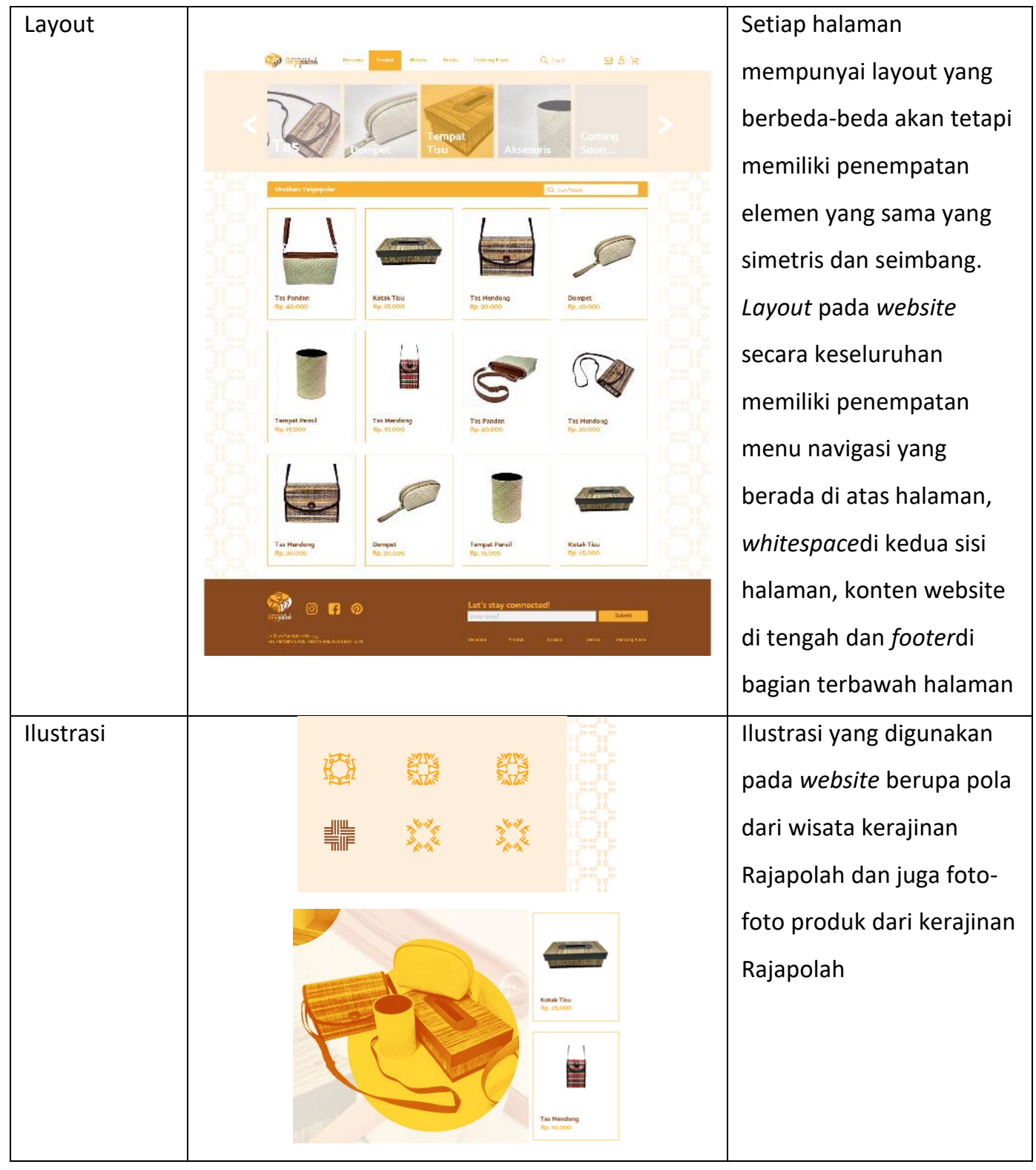




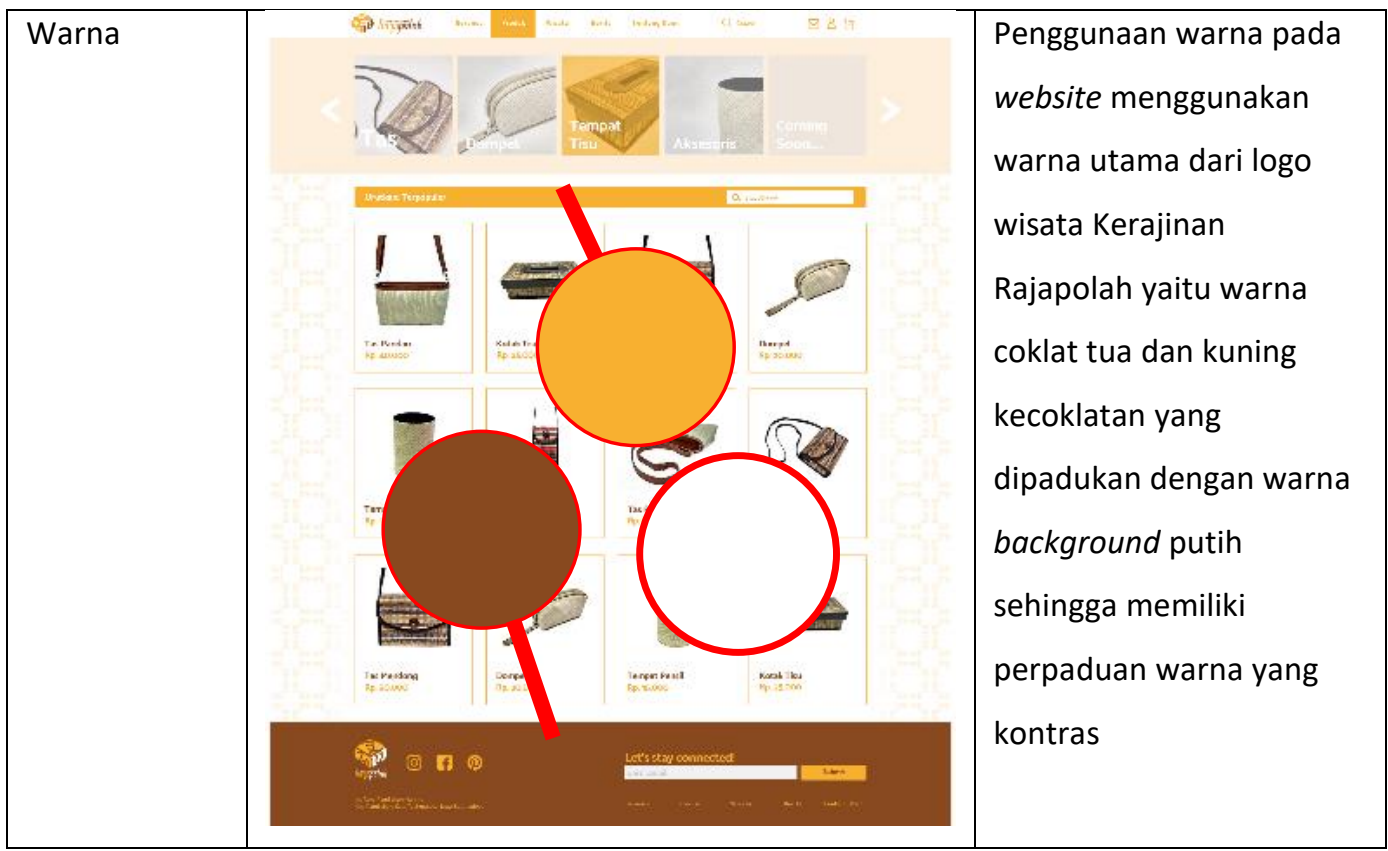

sumber: dokumentasi pribadi

\section{KESIMPULAN}

Penerapan identitas visual pada media promosi website dibutuhkan untuk dapat menjangkau target pasar secara luas dan efektif sekaligus memperkenalkan dan meningkatkan kesadaran akan brand wisata kerajinan Rajapolah. Media promosi website dipilih sebagai media promosi wisata kerajinan Rajapolah karena merupakan salah satu media yang dianggap efektif dalam menjangkau target pasar yang luas dikarenakan website dapat diakses kapanpun dan dimanapun melalui internet yang kini telah banyak digunakan oleh masyarakat. Identitas visual dibutuhkan dalam merancang media promosi website pada keseluruhan desain dan tampilan yang disajikan agar dapat mempermudah kesadaran dan pengenalan terhadap brand sehingga mengembangkan asosiasi terhadap brand Wisata Kerajinan Rajapolah. Dengan dirancangnya identitas visual yang memiliki karakter dari kerajinan Rajapolah dan penerapannya pada media promosi website diharapkan dapat mengenalkan dan mempromosikan Wisata Kerajinan Rajapolah sehingga dapat menjangkau target pasar yang lebih luas danjuga dapat membantu 
meningkatkan daya jual produk kerajinan Rajapolah dengan adanya fitur toko online.

\section{DAFTAR PUSTAKA}

Anggraini, L. \& Kirana, N., 2014. Desain Komunikasi Visual. Bandung: Nuansa Cendekia.

Beaird, Jason. dan George, James. (2014). The Principles Of Beautiful Web Design. 3rd Edition. United States of America: SitePoint Pty. Ltd.

Belch, George E. dan Michael A. Belch. (2012). Advertising and Promotion: An Integrated Marketing Communications Perspective, 9th edition. New York: McGraw-Hill Publishing Company.

Darmastuti, Rini. (2012). Media Relations: Konsep, Strategi dan Aplikasi. Yogyakarta: ANDI.

Dinas Pariwisata dan Kebudayaan Provinsi Jawa Barat. (2016). Pariwisata Kabupate Tasikmalaya. Diakses pada www. disparbud.jabarprov.go.id (03 Maret 2017 21:56).

Wheeler, Alina. (2013). Designing Brand Identity: an Essential Guide for the Whole Branding Team, 4th Edition. Hoboken, New Jersey: John Wiley \& Sons, Inc. Wibowo, Ibnu Teguh. (2013). Belajar Desain Grafis. Yogyakarta: Buku Pintar. 